
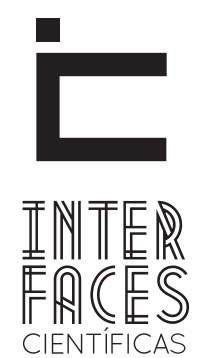

DIREITO

\title{
UMA ANÁLISE SOBRE A RESPONSABILIDADE DO CONSELHO ESTADUAL DE DETERMINAR A TIPOLOGIA PARA O MUNICÍPIO PROMOVER O LICENCIAMENTO DAS ATIVIDADES DE IMPACTO AMBIENTAL - A INCONSTITUCIONALIDADE DO ART. 9 ", XIV, DA LEI COMPLEMENTAR 140/2011
}

\section{RESUMO}

O presente trabalho procura fazer uma análise sobre a responsabilidade do Conselho de Estado de terminar a tipologia para o município promover o licenciamento ambiental das atividades de impacto ambiental. Tal competência está prevista na Lei complementar n. 140/2011 que foi promulgada com a finalidade de fixar normas de cooperação entre os entes federados para as atividades ambientais. 0 objetivo do artigo é tentar demonstrar a inconstitucionalidade do art. $9^{\circ}$, XIV, a da referida lei com base na autonomia do ente federado municipal estabelecida na Constituição Fe- deral de 1988, tendo em vista o federalismo cooperativo estabelecido como forma de estado, além de tentar demonstrar a importância da criação e atuação de órgãos locais na atuação da defesa do meio ambiente em âmbito municipal vez que se encontra em posição privilegiada por estar mais próximo da realidade local.

\section{PALAVRAS-CHAVES}

Competência. Autonomia Municipal. Licenciamento Ambiental. 


\section{ABSTRACT}

This paper attempts to make an analysis about the responsibility of the State Council to end the typology for the city to promote the environmental licensing of activities in environmental impact. Such a capability is provided in Additional Law n. 140/2011 which was enacted in order to establish norms of cooperation among federal agencies for environmental activities. The aim of this paper is to demonstrate the unconstitutionality of Art. 9, XIV, the law of that based on the autonomy of local government level established in the Constitution of 1988, in view of cooperative federalism established as a state form, besides trying demonstrate the importance of the creation and performance of local action in defense of the environment at the municipal level as it is in prime position to be closer to the local reality.

\section{KEYWORDS}

Competence. Municipal Autonomy. Environmental Licensing.

\section{INTRODUÇ̃̃O}

A proteção ambiental é uma responsabilidade compartilhada por todos os indivíduos. Como o bem ambiental é de interesse coletivo e difuso, afeta indiscriminadamente toda a coletividade, sendo necessária sua proteção e preservação para que seja usufruído de forma sustentável para a presente geração e preservado para as futuras.

Os procedimentos administrativos de licenciamento ambiental são de grande importância, face ao seu alto grau de caráter preventivo, tendo em vista que buscam garantir a utilização dos recursos naturais disponíveis de forma racional e devem ser realizados com a máxima observância dos requisitos técnicos para que cumpra a sua finalidade.

\section{RESUMEN}

En este trabajo se trata de hacer un análisis sobre la responsabilidad del Consejo de Estado de finalizar la tipología de la ciudad para promover el licenciamiento ambiental de las actividades de impacto ambiental. Esta capacidad está prevista en la Ley Complementaria n. 140/2011 que se promulgó con el fin de establecer normas de cooperación entre las agencias federales para actividades ambientales. El objetivo de este trabajo es demostrar la inconstitucionalidad del art. 9, XIV, de la ley basada en la autonomía de las ciudades establecida en la Constitución de 1988, en vista del federalismo cooperativo establecido como una forma de Estado, además de tratar de demostrar la importancia de la creación y el funcionamiento de los entes locales en la acción de defensa del medio ambiente en la esfera municipal ya que se encuentra en una posición privilegiada por estar más cerca de la realidad local.

\section{PALABRAS CLAVE}

Competencia. Autonomía Municipal. Licencia Ambiental.

Nesse contexto, o que se percebe é uma distribuição de competências entre os entes federativos para proteger a questão ambiental, o que abordaremos mais especificadamente no transcorrer do presente trabalho. Trata-se de um modelo de gestão compartilhada entre os entes quanto à gestão do meio ambiente. 0 objetivo é garantir uma maior eficácia na proteção do ambiente ecologicamente equilibrado, num processo de somatório de forças.

Em que pese à gestão compartilhada, não se pode perder de vista a distribuição de competências estabelecida pela Constituição da República. É vedado a um 
ente federativo usurpar a competência de outro, sendo os mesmos autônomos para atuarem livremente.

Nessa seara, abordaremos de forma específica a inconstitucionalidade do artigo $9^{\circ}$, inciso XIV, alínea a da Lei Complementar n 140/2011, que representa uma submissão de um ente em relação a outro, uma afronta ao equilíbrio federativo quando limita a determinação da tipologia para realizar o licenciamento ambiental municipal ao Conselho Estadual.

\section{COMPETÊNCIA}

A competência pode ser definida como uma capacidade jurídica de agir em uma esfera determinada (FARIAS, 2011).

José Afonso da Silva (2003) define esse instituto como sendo a modalidade de poder de que se revestem os órgãos ou entidades paraestatais para o desempenho de suas funções, ou a atribuição facultada a um órgão, entidade ou agente do Poder Público para tomar decisões (SILVA, 2003).

Dessa forma, podemos entender que a competência se trata de um critério de distribuir entre os órgãos atribuições para o desempenho de suas atividades.

O Estado brasileiro constitui-se de uma organização administrativa relacionada a essa distribuição de competências. O Brasil na sua Constituição Federal de 1988 adotou como forma de Estado o federalismo e atribuiu a cada ente federativo uma determinada autonomia política, administrativa e normativa, isto é, estabeleceu certa repartição de soberania entre eles.

O federalismo é um modelo constitucional que prevê a descentralização do poder em vários centros autônomos, coordenados por um poder central responsável pelo exercício da soberania. A autonomia dos Estados-membros caracteriza-se por uma capacidade de normatização própria, autogoverno, auto-administração e auto-organização (MORAES, 2007).

A inclusão dos Municípios é uma peculiaridade desse sistema federal brasileiro. No nosso ordenamento jurídico, mais especificamente no caput do artigo $1^{\circ}$ da Constituição Federal estabeleceu-se que: “A República Federativa do Brasil, formada pela união indissolúvel dos Estados e Municípios e do Distrito Federal, constitui-se em Estado Democrático de Direito" (BRASIL, 1988).

Ainda o artigo $18^{\circ}$ da mesma Carta determina a organização político-administrativa da República Federativa do Brasil, explicitando que: "A organização político-administrativa da República Federativa do Brasil compreende a União, os Estados, o Distrito Federal e os Municípios, todos autônomos, nos termos da Constituição" (BRASIL, 1988).

Sendo assim, podemos perceber que a nossa Constituição Federal reconheceu o Município como ente integrante do sistema federativo, integrando-o na organização político-administrativa, garantindo-lhe plena autonomia semelhantemente aos demais entes.

Paulo Bonavides (2007) ao analisar essa inclusão dos Municípios como ente federal, assim se expõe:

Não conhecemos uma única forma de união federativa contemporânea onde o princípio da autonomia municipal tenha alcançado grau de caracterização política e jurídica tão alto e expressivo quanto aquele que consta da definição constitucional do novo modelo implantado no país com a Carta de 1988. (BONAVIDES, 2007, p.129) 
Assim, podemos constatar que ao Município também foi concedida as capacidades de autogoverno, auto-organização, auto-administração e normatização própria.

Essa forma em que o Estado brasileiro é organizado é tão importante que a nossa Constituição Federal coloca-a entre as suas principais garantias, não podendo a mesma ser objeto de qualquer alteração ou mesmo extinção.

0 artigo 60, parágrafo $4^{\circ}$, inciso I, é claro ao impor que: "Não será objeto de deliberação a proposta de emenda tendente a abolir: a forma federativa de Estado" (BRASIL, 1988).

\subsection{COMPETÊNCIA AMBIENTAL}

A Constituição Federal prevê a competência administrativa e a competência legislativa no âmbito da competência ambiental. A competência administrativa cabe ao Poder Executivo e diz respeito à faculdade para atuar com base no poder de polícia, ao passo que a competência legislativa cabe ao Poder Legislativo e diz respeito à faculdade para legislar a respeito dos temas de interesse da coletividade.

José Afonso da Silva (2010) ressalta que a distribuição de competências entre os entes federativos em matéria ambiental segue os mesmos parâmetros adotados pela Constituição Federal em relação às outras matérias, vejamos:

\subsubsection{COMPETÊNCIA LEGISLATIVA}

A competência legislativa está ligada ao Poder Legislativo e diz respeito à competência para legislar. A Constituição Federal de 1988 adotou a competência concorrente e suplementar em matéria ambiental, incluindo assim o licenciamento ambiental.
Umas das principais características do Federalismo é a repartição de competências no âmbito legislativo, administrativo e tributário.

Em regra, essa repartição de competência está diretamente atrelada ao Princípio da predominância do interesse, e é ele que direciona essa distribuição de acordo com o interesse de cada ente para atuação.

As matérias concernentes ao interesse nacional serão atribuídas ao ente federal União; as estaduais também conhecidas como regionais serão atribuídas aos Estados; e aquelas de interesse estritamente local serão de competência do Município, ficando o Distrito Federal acumulando em parte uma competência de interesse estadual e em parte municipal (MORAES, 2007).

A repartição de competência em matéria ambiental, no Brasil, segue os mesmos princípios que a Constituição adotou para a distribuição da competência em geral entre as entidades federativas, União, Estados, Distrito Federal e Municípios têm competência para a proteção ambiental. Encontramos competência material exclusiva, competência material comum, competência legislativa exclusiva e competência legislativa concorrente. (SILVA, 2010, p.75)

Isso implica dizer que em relação ao meio ambiente a competência também está dividida em competência administrativa e competência legislativa.

A competência concorrente é aquela prevista no artigo 24 da Constituição Federal, reservada à União, aos Estados e ao Distrito Federal, cabendo a União, a primazia de legislar sobre normas gerais. 
Está prevista no art. 24 da Constituição, onde se declara competir à União, aos Estados, e ao Distrito Federal legislar sobre florestas, caça, pesca, fauna, conservação da natureza, defesa do solo e dos recursos naturais, proteção do meio ambiente e controle da poluição (inciso IV), sobre proteção ao patrimônio histórico, cultural, artístico, turístico e paisagísticos (inciso VII), assim como sobre responsabilidade por dano ao meio ambiente, a bens e direitos de valor artístico, estético, histórico, turístico e paisagístico (inciso VIII) (SILVA, 2004).

A competência suplementar é aquela atribuída aos Estados, Distrito Federal e aos Municípios a faculdade de complementar os princípios e as normas gerais e a observação de que em matéria ambiental a União pode legislar de forma pormenorizadamente sobre determinado assunto como se estivesse tratando de uma norma geral em busca de uma maior defesa do meio ambiente-ligado ao princípio da prevenção e da precaução ou de suprir a omissão destes, estando previsto nos parágrafos $2^{\circ}$ e $3^{\circ}$ do artigo 24 e no inciso II do artigo 30 da Constituição Federal. (FARIAS, 2011)

Os Municípios podem legislar sobre os temas ambientais de interesse predominantemente local, des-

\subsubsection{COMPETÊNCIA ADMINISTRATIVA}

A competência administrativa está ligada ao Poder Executivo, com base no seu poder de polícia. O Poder Executivo pode usar dessa faculdade para atuação.

A competência administrativa em matéria ambiental se subdivide em competência administrativa exclusiva e competência administrativa comum.

A competência exclusiva é aquela reservada unicamente a um ente. Na nossa Constituição essa competência diz respeito à União e é prevista no artigo 21, incisos XIX, XX e XXIII da Constituição Federal. de que respeite as normas gerais que tiverem sido editadas pela União, pelo Estado ou pelo Distrito Federal.

Na ausência de lei federal, podem os Estados e o Distrito Federal editar normas gerais em matéria ambiental. Se omisso também estes, os Municípios, inexistindo norma geral federal ou estadual sobre o tema, poderão editar normas gerais conforme previsto na Constituição.

Dessa forma, podemos perceber a autonomia dos Municípios no campo legislativo ambiental. Se existirem normas gerais editadas pela União, pelos Estados ou Distrito Federal e sendo essas constitucionais, os Municípios deverão estabelecer suas normas suplementares para melhor adequação à realidade local.

Entretanto, se não existirem tais normas gerais, ou sendo essas inconstitucionais, os Municípios terão autonomia para determiná-las de forma criteriosa para atender de forma diferenciada sua região.

Tendo em vista essa competência estabelecida constitucionalmente, concluímos ser possível a capacidade de normatização própria e auto-administração prevista no nosso Estado Democrático de Direito apresentado na sua forma de estado federal.

Essa competência exclusiva da União se limita à instituição do sistema nacional de gerenciamento de recursos hídricos e à definição de critérios de outorga de direitos para o seu uso, à instituição de diretrizes para o desenvolvimento urbano, inclusive habitação, saneamento básico e transportes urbanos, à exploração dos serviços e instalações nucleares de qualquer natureza, e ao exercício do monopólio estatal sobre a pesquisa, a lavra, o enriquecimento e o reprocessamento, a industrialização e o comércio de minérios nucleares e seus derivados. Essa competência não tem nenhuma relação com o licenciamento ambiental (BRASIL, 1988). 
A competência comum é aquela em que a União, os Estados, o Distrito Federal e os Municípios podem atuar indistintamente e cumulativamente. Está prevista no artigo 23, incisos III, IV, VI, VII, IX e XI da Constituição Federal.

Nesse contexto é competência administrativa comum da União, dos Estados, do Distrito Federal e dos Municípios proteger os documentos, as obras e outros bens de valor histórico, artístico e cultural, os monumentos, as paisagens naturais notáveis e os sítios arqueológicos, impedir a evasão, a destruição e a descaracterização de obras de arte e de outros bens de valor histórico, artístico ou cultural, proteger o meio ambiente e combater a poluição em qualquer de suas formas, preservar as florestas, a fauna e a flora, promo-

\subsubsection{COMPETÊNCIA ADMINISTRATIVA FISCALLZATÓRIA}

A proteção do meio ambiente é comum a todos os entes federativos, que juntos devem promover as ações administrativas em defesa dos problemas ambientais.

A competência administrativa fiscalizatória é a competência para fiscalizar a atividade ou o bem de uma determinada pessoa natural ou jurídica que possa influenciar o meio ambiente e a qualidade de vida da coletividade.

Assim, todos os entes federados possuem a obrigação de defender o meio ambiente, posto que a competência fiscalizatória é comum a todos eles. Todos detêm a competência de atuar na medida de sua jurisdição.

\subsubsection{COMPETÊNCIA ADMINISTRATIVA LICENCIATÓRIA}

Diferentemente do que acontece na competência fiscalizatória, não é recomendável na competência administrativa licenciatória que os entes tenham uma competência comum para promover o licenciamento ambiental. ver programas de construção de moradias e a melhoria das condições habitacionais e de saneamento básico e registrar, acompanhar e fiscalizar as concessões de direitos de pesquisa e exploração de recursos hídricos e minerais em seus territórios (BRASIL, 1988).

Conclui-se assim, que ao delimitar essa competência, confere aos entes federados a atuação de forma cooperativa sobre os assuntos acima delimitados.

A competência administrativa comum em matéria ambiental pode ser dividida em competência administrativa para fiscalizar e competência administrativa para licenciar, tendo em vista que todos os entes possuem o dever de fiscalizar e atuar em relação ao meio ambiente procurando uma melhor proteção e preservação.

Farias (2011) sobre o tema, assim se posiciona ao se expressar que a responsabilidade ambiental não está ligada a fiscalização, mas que a fiscalização é dever de todos os entes, tendo em vista que o objetivo principal a ser buscado é a proteção ao meio ambiente:

É claro que o órgão ambiental responsável pelo licenciamento da atividade é o principal responsável pelo controle ambiental da mesma, mas isso não impede que os outros órgãos ambientais exerçam a sua competência administrativa. Isso está de acordo com a intenção do legislador constituinte, já que dessa forma haverá mais transparência e mais controle social. (FARIAS, 2011, p. 103).

0 ideal é que essa atividade seja realizada de forma integrada pelos entes federativos, tendo em vista que evitaria uma duplicidade de esforços, facilitando e dando um maior equilíbrio na defesa do meio ambiente. 
Por muitas vezes há disputa e reclamações por parte dos entes para quem seja o competente para realizar o licenciamento. Há divergência na doutrina e na jurisprudência e diversos critérios para solucionar a polêmica.

Na verdade, a própria legislação ambiental contribuiu para isso, na medida em que não foi clara nem coerente em seus critérios e direcionamentos.

Diante da ausência de regras claras sobre a repartição de competências administrativas sempre geraram incertezas e dúvidas quanto a qual órgão ambiental a realizar o licenciamento ambiental.

Assim, por estas incertezas e incoerência, Maurício Carneiro Paim (2012, n.p.)assim expõe:

\section{LEI COMPLEMENTAR № 140/2011}

A Lei complementar no 140 de 08 de dezembro de 2011 foi editada com o objetivo de fixar as normas, nos termos no artigo III, VI e VII do caput do artigo 23 da Constituição Federal, para a cooperação entre a União, os Estado, o Distrito Federal e os Municípios nas ações administrativas decorrentes do exercício da competência comum relativas à proteção das paisagens naturais notáveis, à proteção do meio ambiente, ao combate à poluição em qualquer das suas formas e à preservação das florestas, da fauna e da flora e altera a Lei nº 6.938 de 1981 (BRASIL, 2011).

O parágrafo único do artigo 23 da Constituição Federal prevê a edição de leis complementares para a fixação de normas para a cooperação entre a União, os Estados, o Distrito Federal e os Municípios, tendo em vista o equilíbrio do desenvolvimento e do bem-estar em âmbito nacional.
Os princípios constitucionais da predominância de interesse e da eficiência administrativa que, especialmente, ante a ausência da referida regulação, deveriam nortear a atuação dos órgãos incumbidos de promover a defesa e a proteção do meio ambiente não se revelam suficientes para evitar ações dúplices, desperdícios de recursos públicos, nem para oferecer à sociedade a segurança jurídica necessária.

A resolução n 237/97 do CONAMA estabeleceu critérios e parâmetros para a repartição de competências entre os entes para realizar o licenciamento ambiental.

Porém, conforme estabelece o parágrafo único do artigo 23 da Constituição Federal era necessário a instituição de Lei complementar para disciplinar a matéria.

A Lei complementar $n^{0} 140 / 2011$ surge assim como forma de suprir a lacuna existente em nosso ordenamento jurídico.

Um dos princípios objetivadores dessa lei é o Princípio da não-superposição dos entes estatais. Tal princípio visa evitar que os mesmos entes façam a mesma coisa juntos ao mesmo tempo (KOKKE, 2012)

0 ideal é que eles trabalhem de forma integrada, evitando a duplicidade de esforços, a perca de eficiência e produtividade para a sociedade, sendo que o objetivo principal é tornar a proteção ao meio ambiente na forma mais eficaz possível (KOKKE, 2012) 


\subsection{COMPETÊNCIA}

A referida lei complementar estabelece que as ações de cooperação entre a União, os Estados, o Distrito Federal e os Municípios deverão ser desenvolvidas de modo a atingir e garantir o desenvolvimento sustentável harmonizando e integrando todas as políticas governamentais.

Em seu artigo $7^{\circ}$, inciso XIV prevê que são ações administrativas da União promover o licenciamento ambiental de empreendimentos e atividades localizados ou desenvolvidos conjuntamente no Brasil e em país limítrofe; localizados ou desenvolvidos no mar territorial, na plataforma continental ou na zona econômica exclusiva; localizados ou desenvolvidos em terras indígenas; localizados ou desenvolvidos em unidades de conservação instituídas pela União, exceto em Áreas de Proteção Ambiental (APAs); localizados ou desenvolvidos em 2 (dois) ou mais Estados; de caráter militar com suas exceções; destinados a pesquisar, lavrar, beneficiar, transportar, armazenar e dispor material radioativo, em qualquer estágio, ou que utilizem energia nuclear em qualquer de suas formas e aplicações, mediante parecer da Comissão Nacional de Energia Nuclear (Cnem); ou que atendam tipologia estabelecida por ato do Poder Executivo, a partir da proposição da Comissão Tripartite Nacional, assegurada a participação de um membro do Conse-

\subsection{AUTONOMIA DO MUNICÍPIO}

A competência estabelecida na Constituição Federal tem previsão que Lei complementar estabelecerá a cooperação entre União, Estados, Distrito Federal e Municípios tendo em vista o equilíbrio do desenvolvimento e bem-estar em âmbito nacional.

Dessa forma, cabe ao operador do direito a construção de um sistema adequado à implementação do federalismo cooperador, o que não está realçado no artigo explicitado, pois que o Municí-
Iho Nacional do Meio Ambiente (Conama), e considerados os critérios de porte, potencial poluidor e natureza da atividade ou empreendimento (BRASIL, 2011).

São ações administrativas do Estado conforme estabelece o artigo $8^{\circ}$, incisos XIV e XV, promover o licenciamento ambiental de atividades ou empreendimentos utilizadores de recursos ambientais, efetiva ou potencialmente poluidores ou capazes, sob qualquer forma, de causar degradação ambiental, e promover o licenciamento ambiental de atividades ou empreendimentos localizados ou desenvolvidos em unidades de conservação instituídas pelo Estado, exceto em Áreas de Proteção Ambiental (APAs) (BRASIL, 2011).

Já as atividades administrativas dos entes municipais previstas no artigo $9^{\circ}$, XIV, observadas as atribuições dos demais entes federativos previstos na lei, caberá a eles promover o licenciamento ambiental das atividades ou empreendimentos que causem ou possam causar impacto ambiental de âmbito local, conforme tipologia definida pelos respectivos Conselhos Estaduais de Meio Ambiente, considerados os critérios de porte, potencial poluidor e natureza da atividade, ou localizados em unidades de conservação instituídas pelo Município, exceto em Áreas de Proteção Ambiental (APAs) (BRASIL, 2011).

pio para realizar o licenciamento ambiental está vinculado a uma determinação da tipologia do Conselho Estado.

O licenciamento é um dos mais importantes pilares da política ambiental por representar um dos instrumentos fundamentais na defesa dos recursos naturais, ao mesmo tempo, que constitui uma segurança jurídica para a sociedade. 
É uma preocupação constante tanto dos indivíduos como do Poder Público, a defesa do meio ambiente e das atividades que possam causar impactos ambientais.

Importante se faz assim que haja um trabalho cooperativo, sem vinculações nem submissões autoritárias entre os entes para que se busque a certeza do preceito constitucional de desenvolvimento sustentável.

Quanto ao município, a repercussão ambiental da atividade ou empreendimento é restrita geralmente aos limites municipais, caracterizando-se por um interesse preponderantemente local. p. 432):

Com isso, a lição do doutrinador Édis Milaré (2011,

Atento a isso, o Conselho Nacional do Meio Ambiente, no exercício da sua competência de estabelecer normas técnicas e administrativas para a execução das regras gerais e abstratas contidas na Lei n. 6.938/81, editou a Resolução CONAMA n. 237/97, reordenando o licenciamento ambiental em todo o território nacional, dando ênfase ao município como ente federativo e atribuindo-lhe funções específicas na gestão do meio ambiente, em particular no que refere aos interesses locais.

A resolução do CONAMA n ${ }^{0} 237$ já observa as competências constitucionais que insere o município na administração do licenciamento ambiental.

Nesta resolução, a competência estabelecida nas três esferas é distribuída da seguinte forma: compete ao IBAMA, na esfera federal, o licenciamento ambiental de empreendimentos de âmbito nacional ou regional; ao órgão ambiental estadual ou ao Distrito Federal, compete o licenciamento ambiental dos empreendimentos cujos impactos ambientais dire-

\section{3 ÓRGÃOS LOCAIS}

A Lei nº 6.938/91 definiu órgãos locais como sendo "os órgão e entidades municipais responsáveis tos ultrapassem os limites territoriais de um ou mais Municípios; e ao órgão ambiental municipal cabe o licenciamento de empreendimentos e atividades de impacto ambiental local e daqueles que the forem delegadas pelo Estado, por instrumento legal ou convênio (BRASIL, 1997).

Temos também mais exemplos na Constituição Federal de 1988 que prevê a importância dessa atuação autônoma do Município, como exemplo o artigo 182 e 183, que prevê o Estatuto da Cidade, Lei no 10.257 de 2001.

Sobre a autonomia dos Municípios na Constituição de 1988 afirma o saudoso mestre Hely Lopes Meirelles (1917, p. 37-38):

A posição atual dos Municípios brasileiros é bem diversa da que ocuparam nos regimes anteriores. Libertos da intromissão discricionária dos governos federal e estadual e dotados de rendas próprias para prover os serviços locais, os Municípios elegem livremente seus vereadores, seus prefeitos e vice-prefeitos e realizam o self-government de acordo com a orientação política e administrativa dos seus órgãos de governo. Deliberam o executando tudo quanto respeite ao interesse local, sem consulta ou aprovação do governo estadual ou federal. Decidem da conveniência ou inconveniência de todas as medidas de seus interesses; entendem-se diretamente com todos os Poderes da República e do Estado, sem dependência hierárquica à administração federal ou estadual.

Portanto, implica em afronta à capacidade de auto-organização do Município a imposição de submissão a órgãos de entes diversos acerca da execução de seus atos administrativos. Essa infrigência constitui usurpação de competência, que afeta o equilíbrio entre os entes federativos, devendo ser combatido de forma peremptória. pelo controle e fiscalização dessas atividades, nas suas respectivas jurisdiç̧̃es.” (BRASIL, 1991). 
Além disso, o decreto $n^{\circ}$ 99.274/90 indica que os órgãos ou entidades municipais são responsáveis pelo controle e fiscalização das atividades referidas no inciso anterior, nas suas respectivas jurisdições.

O Sistema Nacional de Meio Ambiente (SISNAMA) foi instituído pela Lei Federal $n^{\circ} 6.938$ de 31 de agosto de 1981, sendo composto por órgãos da União, Estados, Distrito Federal e Municípios.

O SISNAMA é estruturado da seguinte forma: 1) Órgão Superior, Conselho de Governo, com a função de assessorar o Presidente da República na formulação da política nacional e nas diretrizes governamentais para o meio ambiente e os recursos ambientais; 2) Órgão Consultivo e Deliberativo, Conselho Nacional de Meio Ambiente (CONAMA), com a finalidade de assessorar, estudar e propor ao Conselho de Governo diretrizes políticas governamentais para o meio ambiente e os recursos naturais e deliberar, no âmbito de sua competência, sobre normas e padrões compatíveis com o meio ambiente ecologicamente equilibrado e essencial à sadia qualidade de vida; 3) Órgão Central, Ministério do Meio Ambiente (MMA), com a finalidade de planejar, coordenar, supervisionar e controlar, como órgão federal, a política nacional e as diretrizes governamentais fixadas para o meio ambiente; 4) Órgãos Executores, Instituto Brasileiro do Meio Ambiente e dos Recursos Naturais Renováveis (IBAMA), Instituto Chico Mendes de Proteção à Biodiversidade (ICMBio) e Agência Nacional das Águas (ANA), com a finalidade de executar, como órgãos federais, a política de diretrizes governamentais fixadas para o meio ambiente; 5) Órgãos Seccionais, órgãos ou entidades estaduais, responsáveis pela execução de programas, projetos e pelo controle e fiscalização de atividades capazes de provocar a degradação ambiental; 6) Órgãos locais: órgãos ou entidades municipais, responsáveis pelo controle e fiscalização dessas atividades, nas suas respectivas jurisdições. (Ministério do Meio Ambiente e RIBEIRO, 2012)

Os Estados poderão elaborar normas e padrões complementares desde que observados os que forem estabelecidos pelo CONAMA. Os Municípios, observadas as normas e os padrões federais e estaduais, também poderão elaborar as normas.

Esses órgãos ou entidades municipais estão ligados diretamente ou indiretamente em prol da proteção da qualidade ambiental ou ao disciplinamento do uso de recursos ambientais.

Não se pode perder de vista a autonomia dos órgãos locais. Ao reconhecê-la, cabe destacar:

Da mesma forma que os Órgãos Setoriais, os Locais, não sofrem coordenação por parte de quaisquer órgãos ou entidades federais ou estaduais. De outra forma estaria ferindo a autonomia municipal que a Constituição sempre garantiu expressamente desde 1891. (OLIVEIRA, 2005, p. 216).

Como já citado, há a previsão da organização político-administrativa no art.18 da Constituição Federal e que prevê a autonomia dos entes federados.

Portanto, no que tange aos órgãos locais do SISNAMA (assim como as seccionais) não se cogita qualquer espécie de subordinação ou coordenação (OLIVEIRA, 2005, p. 217).

Mesmo expondo no que se refere à competência fiscalizatória dos entes, podemos usar de tal argumento para defender a competência licenciatória, vejamos:

Em lugar de manter uma luta surda com os Estados e Municípios pelo poder de fiscalizar as ações destes, que em alguns casos chega mesmo ao enfrentamento frontal, com o consequente desgaste para ambas as partes, seria muito mais produtivo que, cumprindo a legislação, limitasse suas ações ao caráter meramente supletivo que lhes são inerentes, e dedicasse seus esforços em efetivamente apoiar e propiciar articulação as ações municipais e estaduais, mantendo-os sempre informados das ações federais e de outros Municípios ou Estados, que possam contribuir para o aperfeiçoamento dos órgãos seccionais e locais. (OLIVEIRA, 2005, p. 218). 
Paulo Affonso Leme Machado (2010) ainda sobre o assunto, assim se manifesta:

A questão ambiental, hoje, inclusive pelo enfoque constitucional, não pode ser circunscrita à ação de uma só repartição pública, por mais alta que seja sua hierarquia. Na verdade, ela deveria ser preocupação presente na ação de todos os Poderes da República, mormente o Executivo. A questão é tão abrangente que, na realidade prática, todos os Ministérios e Secretarias integram o SISNAMA, uma vez que todos são responsáveis pela proteção e melhoria da qualidade

\subsection{A INCONSTITUCIONALIDADE DO ARTIGO 9º, INCISO XIV, ALÍ- NEA A, DA LEI COMPLEMENTAR 140/2011}

Como vimos no primeiro capítulo, a competência estabelecida pela Constituição Federal quanto à realização do licenciamento ambiental, prevista em seu artigo 23, é uma competência comum a todos os entes.

Sendo assim, como forma de facilitar o trabalho dos órgãos ambientais e da proteção ao meio ambiente, conforme previsto no parágrafo desse artigo supracitado, a Lei complementar, tendo como pano de fundo um federalismo cooperativo delimitou as ações administrativas de cada ente conforme foi citado anteriormente.

O critério para essa determinação foi baseado em um federalismo cooperativo e com base no Princípio da Predominância do interesse, sendo facilitador a atuação de cada ente na região de seu interesse de atuar.

Ocorre que a Lei complementar $n^{0} 140 / 2011$ ao determinar a competência das ações administrativas dos Municípios, limitou-as a uma ingerência de determinado órgão do Estado, o que fere a autonomia dos entes federativos na elaboração de seus planejamentos próprios, garantia assegurada pela Constituição da República de 1988. ambiental, por expresso mandamento constitucional. (MACHADO, 2010, p. 90).

Essa orientação visa a proteção ambiental em sua integralidade e em todas as suas vertentes, face à sua importância como bem coletivo e de interesse difuso, conforme expresso no artigo 225 da Constituição Federal. Não podendo, dessa forma, os municípios ficarem vinculados a um ente "hierarquicamente" superior, impedidos de exercer sua autonomia.

0 artigo $9^{\circ}$, inciso XIV, alínea a da Lei complemen$\operatorname{tar} n^{0} 140 / 2011$ assim prevê:

Art. 90- São ações administrativas dos Municípios: XIV- observadas as atribuições dos demais entes federativos previstas nesta Lei Complementar, promover o licenciamento ambiental das atividades ou empreendimentos: a) que causem ou possam causar impacto ambiental de âmbito local, conforme tipologia definida pelos respectivos Conselhos Estaduais de Meio Ambiente, considerados os critérios de porte, potencial poluidor e natureza da atividade. (BRASIL, 2011).

Conforme o estabelecido na alínea a, os Conselhos Estaduais que detém a competência para determinar a tipologia definida para que os Municípios realizem o licenciamento ambiental.

A aludida afronta à distribuição de competências prevista na Constituição, no que concerne especificadamente à Lei Complementar $n^{0} 140$, é flagrante ante a submissão imposta aos municípios, cuja atuação fica condicionada à deliberação de órgão diverso da sua esfera.

O conflito se mostra presente no próprio texto legal da alínea acima descrita. 0 caput do art. $9^{\circ}$ estabelece que "são ações administrativas dos Municípios". Ou seja, o artigo introduz as ações administra- 
tivas de competência exclusiva do Município, sendo claro pelo texto legal a restrição feita ao ente municipal. Não obstante, a alínea a, a contrário senso, impõe a contradição: "conforme tipologia definida pelos respectivos Conselhos Estaduais de Meio Ambiente". Ora, o conflito é cristalino na medida em que o caput do artigo $9^{a}$ estabelece as ações do Município, e a alínea citada, nada mais faz que retirar uma prerrogativa de ação administrativa do Município, na medida em que impõe condições a serem reguladas por um órgão pertencente a um ente federativo diverso.

A melhor técnica processual não foi observada na formulação do dispositivo legal. A alínea afronta o caput do referido artigo, estabelece uma submissão do ente municipal à discricionariedade do órgão estadual, o que induz a conclusão que o trecho do caput "são ações administrativas dos Municípios”, não corresponde a real atribuição da capacidade administrativa destes entes para produzir o licenciamento ambiental. Pela alínea a, as referidas ações administrativas são do Município e do Estado, através de seu órgão estadual que deve agir de forma autoritária determinando a decisão final.

O dispositivo legal supracitado nada mais faz do que atribuir uma competência a um ente federativo em seu caput, e na alínea seguinte retirar essa competência e transferi-la a outro ente, in casu, aos estados através de seu conselho estadual.

Ainda nessa análise, a alínea produz um fenômeno de conflito de competências, o que fere preceito constitucional. A imposição da submissão por parte do Município ao órgão do ente estatal fere frontalmente a autonomia dos municípios. Essa submissão não encontra guarida Constitucional, é o que se questiona no presente artigo, assentado no sistema de federalismo que vigora no Brasil.

Noutro plano, cabe dizer que pode existir no âmbito municipal a Secretaria Municipal de Meio Ambiente com o objetivo de executar atividades de gestão da política de meio ambiente, abrangendo o controle e a fiscalização ambiental.

Em geral podemos perceber que essa atuação abarca um leque grande de atividades, como no município de Belo Horizonte em que essa Secretaria tem a competência, principalmente de: formular as normas técnicas e os padrões de proteção, conservação e melhoria do meio ambiente; estabelecer as áreas em que a ação do Executivo Municipal, relativa à qualidade ambiental, deve ser prioritária; atuar no sentido de formar consciência política da necessidade de proteger, melhorar e conservar o meio ambiente; coordenar e elaborar planos, pesquisas, projetos e atividades para implementação da política ambiental e prestar suporte técnico ao Conselho Municipal de Meio Ambiente (COMAM), órgão colegiado responsável pela formulação de diretrizes da Política Municipal de Meio Ambiente e pela outorga da Licença Ambiental (Prefeitura de Belo Horizonte).

Assim, temos a possibilidade de existir um ConseIho Municipal de Meio Ambiente para atuar nas atividades de âmbito local, principalmente nas questões de licenciamento, e não estar vinculado necessariamente e de forma autoritária a um Conselho Estadual.

No caso de Belo Horizonte, por exemplo, existe o Conselho Municipal do Meio Ambiente do Município de Belo Horizonte, que foi criado pela Lei Municipal n 4.235 de Dezembro de 1985. É um órgão colegiado, com ação normativa e assessoramento, responsável pela formulação das diretrizes da Política Municipal de Meio Ambiente de Belo Horizonte, composto de: um Presidente, que é o Secretário Municipal de Meio Ambiente; 7 (sete) representantes do Poder Público Municipal; 7 (sete) representantes da sociedade civil organizada (Prefeitura de Belo Horizonte).

Tal órgão tem um importante papel na formulação e condução da política ambiental em Belo Horizonte, através de um processo aberto à população, notadamente através de realização de audiências públicas. 
É indiscutível que a proximidade com a realidade permite ao conselho municipal uma melhor segurança na tomada de decisões, eis que o contato com as circunstâncias locais específicas resulta em uma análise mais bem apurada.

Entre suas competências, podemos relacionar: a promoção de medidas destinadas à melhoria da qualidade de vida no município; a formulação de normas técnicas e padrões de proteção, conservação e melhoria do meio ambiente para o Município de Belo Horizonte, observadas as legislações federal e estadual; a concessão de licenças para implantação e operação de atividades potencialmente poluidoras; a aprovação das normas e diretrizes para o Licenciamento Ambiental no município; atuação no sentido de formar consciência pública da necessidade de proteger, conservar e melhorar o meio ambiente.

Temos assim, novamente que "Não compete a órgão estadual, ainda que colegiado e representativo, a definição das hipóteses de impacto local, limitando de forma impositiva o exercício da competência ambiental municipal. Deveria ser no mínimo garantida a participação dos municípios na tomada dessa decisão (PAIM, 2012, n.p.).

\subsection{CASO DA BAHIA}

Tem-se como um exemplo o que ocorreu no Estado da Bahia, seu Conselho Estadual de Meio Ambiente (CEPRAM), antes mesmo da vigência da Lei complementar n0140, já havia editado uma Resolução de no 3.925/09 definindo as atividades de impacto local para fins de licenciamento ambiental municipal (PAIM, 2012, n.p.).

Ocorre que nesse conselho não existia qualquer representação do Poder Público municipal na sua composição. Apesar dessa resolução prever sobre programa estadual de gestão ambiental compartilhada com fins ao fortalecimento da gestão ambiental, mediante
Na pior das hipóteses, seria mais factível a submissão a uma comissão representativa de todos os entes federados. "A definição de novas hipóteses de licenciamento no âmbito federal passa pela análise da Comissão Tripartite Nacional. Não se compreende por que razão essa atividade não foi estabelecida como de competência das Comissões Tripartites Estaduais" (PAIM, 2012, n.p.).

As Comissões Tripartites são aquelas em que há representação colegiada e nos vários âmbitos.

A verdade é que não compete a órgão estadual, mesmo que colegiado e tendo representativa por agente do âmbito municipal, definir as hipóteses de impacto local, limitando, dessa forma, o exercício da competência ambiental municipal. No mínimo, como vimos, a constituição deve ser garantida para a participação dos municípios na tomada da decisão.

Ainda assim, mesmo que estivesse determinado na alínea que a Comissão a decidir seria uma comissão com representação municipal, isto é, tripartite, ainda assim feriria o constitucionalmente protegido.

normas de cooperação entre os sistemas municipal e estadual, apoiando a descentralização da gestão ambiental, com o objetivo de fortalecer o sistema municipal de meio ambiente, com celebração de termo de cooperação técnica entre os entes, não é relevante por já existir constitucionalmente a autonomia municipal para tal competência (PAIM, 2012, n.p.).

0 termo de cooperação ou de qualquer outro meio ou instrumento de cooperação entre Município e Estado não se faz necessário, vez que já é previsto essa autonomia municipal. 


\subsection{CASO DE RECIFE}

Estamos agora diante de uma pesquisa a uma cartilha montada com a finalidade de demonstrar a experiência do Município de Recife e sua competência e benesses com a instituição de órgãos para solucionar seus problemas mais de perto, por ser o município o principal conhecedor da sua realidade.

Essa é uma realidade que não pode ser desconsiderada, se o órgão estiver mais próximo da realidade, a sua capacidade de atuação será mais qualificada, e os problemas poderão ter uma solução mais rápida e com uma maior segurança de conhecimento.

Grande parte dos problemas que afetam o meio ambiente e a qualidade de vida das pessoas ocorre no município. E a partir dele podem ser empreendidas ações capazes de preveni-los e solucioná-los. Mais que isso, o município é o local onde se podem buscar caminhos para um desenvolvimento que harmonize o crescimento econômico com o bem-estar da população.

A preocupação com a qualidade ambiental vem crescendo nos municípios brasileiros. Por isso, tem-se criados mecanismos para aumentar a consciência e promover a mudança de hábitos e de comportamentos. Cada vez mais a população atua conscientemente com o Poder Público para participar da gestão do meio ambiental.

É nesse sentido que a criação do órgão municipal pode adquirir uma enorme relevância.

$\mathrm{Na}$ faculdade e compromisso de exercer suas competências atribuídas constitucionalmente, Recife agiu como defensor do meio ambiente, construindo ao longo de anos uma estrutura administrativa para tratar de questões ambientais.

Tal estrutura instituída por esse município seguiu a estrutura baseada no SISNAMA, sendo composta pelo COMAM, pelo Fundo Municipal de Meio Ambiente (FMMA) e pelo órgão de gestão ambiental, Diretoria de Meio Ambiente (RECIFE, 2009).

De acordo com a cartilha, "o licenciamento ambiental do município de Recife foi estabelecido por normas legais que o regraram, hamonizaram-no ao funcionamento do Sistema Municipal de Meio Ambiente. A elaboração destas normas teve como norte a proteção ambiental e, ao mesmo tempo, a possibilidade de que o empreendedor obtenha a licença ou autorização de seu interesse no menor tempo e custo possíveis” (RECIFE, 2009).

Os instrumentos legais que estabeleceram as normas para o licenciamento ambiental foram a Lei Municipal n 16.243, de 13 de Setembro de 1996 em que cria o Código de Meio Ambiente e de Equilíbrio Ecológico da Cidade de Recife, alterada pela Lei municipal no 17.171/05; também a Lei Municipal n 17.071, de 31 de Dezembro de 2004 que institui a taxa de licenciamento ambiental municipal, alterada pela Lei municipal n 17.171/05; e o Decreto Municipal n² 24.540, de 08 de Junho de 2009 que regulamenta o Código de Meio Ambiente, no capítulo que trata de licenciamento e a Lei Municipal n 17.071/2004 (RECIFE, 2009).

ções, empreendimentos e atividades dentro do âmbito do município. Meio Ambiente (SMAM) exerce gestão ambiental fiscalizando e autorizando, mediante condições e restri- 
A Lei municipal $n^{0} 8267 / 98$ instituiu o licenciamento no âmbito municipal com o objetivo de representar uma otimização dos procedimentos de gestão pública, possibilitando que as decisões administrativas sejam cada vez mais integradas, reunindo secretarias e departamentos municipais nas aprovações de atividades (ARIOLI, 2012, n.p.).

Tal lei instituiu a base legal, a competência e os procedimentos para sua realização, o que foi realizado por um convênio firmado entre a Fundação Estadual de Proteção Ambiental, com a interveniência da Secretaria Municipal do Meio Ambiente (ARIOLI, 2012, n.p.). "Para avaliação da degradação ambiental e do impacto das atividades é considerado o reflexo do empreendimento no meio urbano incorporando as variáveis: ambiente natural, ambiente social, cultural local, infra-estrutura, desenvolvimento econômico e social." (ARIOLI, 2012, n.p.).

\subsection{CONSIDERACÕES FINAIS}

A Constituição Federal de 1988 em seu artigo 225 estabelece como um direito comum o usufruto de um meio ambiente ecologicamente equilibrado, considerando que o mesmo é um bem de uso comum e essencial à sadia qualidade de vida.

Compete tanto à coletividade como ao Poder Público o dever de defendê-lo e preservá-lo para as presentes e futuras gerações.

Dessa forma, a criação de um Conselho de meio ambiente deve envolver ativamente a população de determinado município. As pessoas precisam receber informações necessárias e assim saberão seus direitos e suas obrigações se sentindo responsáveis pela qualidade ambiental do local onde habitam.

A criação de um Conselho ativo e de composição democrática atende ao enunciado constitucionalmente protegido. Ao mesmo tempo, o trabalho em
Se o órgão ambiental estabelecer, baseado no impacto a ser geral, poderá exigir do empreendimento a aplicação de instrumentos ambientais como o EIA/ RIMA ou o Relatório de Impacto Ambiental (ARIOLI, 2012. n.p.). "A municipalização do licenciamento promoveu uma mudança de conceitos na prefeitura como um todo, integrando secretarias e departamentos municipais na gestão pública ao licenciar empreendimentos e atividades, aplicando medidas mitigadoras e compensatórias, oriundas dos instrumentos ambientais" (ARIOLI, 2012, n.p.).

A partir da análise dos instrumentos ambientais estabelecem-se as mitigações e compensações de forma que o empreendimento se constitua num fator que permita um real desenvolvimento social e ambiental na cidade de Porto Alegre.

prol de uma descentralização administrativa, responsabiliza a cada dia mais os municípios, chamando-os a assumirem suas responsabilidades.

Isso exige que os seus políticos e cidadãos conheçam mais sobre as questões ambientais. Sendo o conselho, por excelência, um fórum de debates e de construções de conhecimento sobre o ambiente local.

O município também é um espaço adequado para administrar conflitos, propor acordos e construir propostas de gestão que estejam em acordo com os interesses econômicos, sociais e ambientais locais.

Os administradores devem criar condições para que sejam instalados órgãos ambientais municipais com capacidade técnica suficiente para dar apoio aos Conselhos.

Além disso, o executivo municipal deve se esforçar ao máximo para colocar em prática todas as de- 
cisões do conselho pra que este se torne um efetivo instrumento de promoção de qualidade ambiental do município.

Assim, os municípios só têm a ganhar. A instituição de órgãos para solucionar os problemas mais próxi- mos da sua realidade, contarão com uma capacidade de atuação mais qualificada e os problemas poderão ter uma solução mais rápida com maior segurança de conhecimento.

\section{CONCLUSÃO}

Pela própria dinâmica da questão ambiental, é cristalino afirmar que a responsabilidade ambiental deve ser compartilhada por todos os entes federados, com o objetivo de reduzir os riscos e maximizar o desempenho na satisfação do princípio constitucional do meio ambiente ecologicamente equilibrado.

Não obstante, não se deve perder de vista a distribuição de competências específicas, que serve de parâmetro para atribuição das responsabilidades, bem como para delimitar o papel de cada ente a ser desempenhado.

Sendo assim, qualquer afronta ao critério de competência constitui afronta constitucional, face à autonomia dos entes federados.
Destaca-se que a usurpação de prerrogativa de um ente em relação a outro deve ser combatida, sob pena de comprometer o pacto federativo.

No presente trabalho procedemos a uma análise especificadamente do artigo 9, XIV, a da Lei complementar 140/2011, que pelas razões e fundamentos aqui apresentados, concluímos que está eivado de inconstitucionalidade, constitui flagrante afronta à autonomia dos municípios assegurada pela Constituição Federal.

\section{REFERÊNCIAS}

ARIOLI, Magda C. S; LIMA, Claudia B. S.; SCHIMITT, Nara I. M. O desafio do licenciamento ambiental no município de Porto Alegre. Procempa. Disponível em: <http://lproweb.procempa.com.br/pmpa/prefpoa/smam/ usu_doc/magda.pdf>. Acesso em: 07 out. 2012.

BRASIL. Constituição (1988). Constituição da República Federativa do Brasil. 28. Ed. São Paulo: Atlas, 2007.

BRASIL. Lei complementar n. 140 de 8 de Dezembro de 2011. Fixa normas, nos termos dos incisos III, VI e VII do caput e do parágrafo único do art. 23 da Constituição Federal, para a cooperação entre a União, os Estados, o Distrito Federal e os Municípios nas ações administrativas decorrentes do exercício da competência comum relativas à proteção das paisagens naturais notáveis, à proteção do meio ambiente, ao combate à poluição em 
qualquer de suas formas e à preservação das florestas, da fauna e da flora; e altera a Lei n ${ }^{\circ} 6.938$, de 31 de agosto de 1981. Diário Oficial da União, Brasília, 8 dez 2011.

GUERRA, Sidney. Competência ambiental à luz da Lei complementar 140/2011, 2011.

BONAVIDES, Paulo. Curso de Direito Constitucional. 21. ed. São Paulo: Malheiros editores, 2007.

CANOTINHO, José Joaquim Gomes, LEITE, José Rubens Morato, (Org). Direito Constitucional brasileiro. 4. ed. rev. São Paulo: Saraiva, 2011.

CARVALHO, Michelle Aurélio de Carvalho. Os desafios do licenciamento ambiental municipal. Conpedi. Disponívelem:<http://www.conpedi.org.br/manaus/arquivos/Anais/Michelle\%20Aurelio\%20de\%20Carvalho. pdf.> Acesso em: 7 out. 2012.

CAVALCANTI, Romero Duarte Suassuna. Licenciamento ambiental municipal e cooperação com os demais entes. Conteúdo Jurídico. Brasilia: 23 abr. 2012. Disponível em:<http://www.conteudojuridico.com.br/ artigo,licenciamento-ambiental-municipal-e-cooperacao-com-os-demais-entes,36536.html> Acesso em: 25 nov.2012.

CURT, Trennepohl, TRENNEPOHL, Terence. Licenciamento ambiental. 3.ed. Niterói: Impetus, 2010.

FARIAS,Talden. Licenciamento ambiental: aspectos teóricos e práticos. 3. ed. Belo Horizonte: Fórum, 2011.

KOKKE, Marcelo. Palestra: Licenciamento Ambiental e competência administrativa: Lei complementar n. 140/11. Belo Horizonte, PUC-Minas, Faculdade Mineira de Direito. I Seminário Cidade, Direito Urbano e Ambiental, 2012.

MACHADO, Paulo Affonso Leme. Direito Ambiental Brasileiro. 18. ed. São Paulo: Malheiros, 2010.

MEIRELLES, Hely Lopes. Direito Municipal Brasileiro. 6. ed. São Paulo: Malheiros, 1917.

MILARÉ, Édis. Direito do Ambiente. 7. ed. São Paulo: Revista dos Tribunais, 2011.

MINISTÉRIO DO MEIO AMBIENTE. Disponível em:<www.mma.gov.br>. Acesso em: 9 out. 2012.

MORAES, Alexandre de. Direito Constitucional. 22. ed. São Paulo: Atlas, 2007.

OLIVEIRA, Antônio Inagê de Assis Oliveira. Introdução à legislação ambiental brasileira e licenciamento ambiental. Rio de Janeiro: Lumen Juris, 2005.

PAIM, Maurício Carneiro. Lei complementar n.140/11: primeiras impressões. InterTox. Disponível em: <http://www.intertox.com.br/index.php/toxicologia-em-manchete/312-lei-complementar-n-140-11-primeiras-impressoes>. Acesso em: 9 out. 2012. 
PREFEITURA MUNICIPAL DE BELO HORIZONTE. Disponível em: <www.pbh.pbh.gov.br>. Acesso em: 9 out. 2012.

RECIFE. Licenciamento ambiental municipal: manual técnico. Recife: Secretaria de Planejamento participativo, Obras e Desenvolvimento Urbano e ambiental. Recife, 2009. Disponível em: <http://www.recife.pe.gov.br/ noticias/arquivos/1429.pdf>. Acesso em: 9 out. 2012.

RIBEIRO, José Cláudio Junqueira. Curso de especialização em meio ambiente: Gestão ambiental. Belo Horizonte, 2012.

RIBEIRO, José Cláudio Junqueira. Licenciamento ambiental e Judicialização. Belo Horizonte: FEAM, 2002.

SANTOS, Benevenuto. Federalismo e Desenvolvimento Urbano. UniFOA. Disponível em: <http://www.unifoa. edu.br/cadernos/edicao/01/55.pdf>. Acesso em 9 out. 2012.

SILVA, José Afonso da. Direito ambiental constitucional. 4. ed. São Paulo: Malheiros, 2003.

SILVA, José Afonso da. Direito urbanístico brasileiro. 6. ed. São Paulo: Malheiros, 2010. 